WIENER SLAVISTISCHES JAHRBUCH, Band 55/2009, 221-234

(C) 2009 by Österreichische Akademie der Wissenschaften, Wien

ROMAN MNICH

\title{
Из истории одного протокола: материалы Дмитрия Чижевского в архиве Венского университета
}

Венский эпизод в жизни Дмитрия Чижевского (1894-1977) до сегодня не привлекал особого внимания исследователей ${ }^{1}$. В опубликованых материалах и источниках о жизни и творчестве этого энциклопедического учёного только мимоходом упоминается, что в 1938-ом году он старался получить кафедру в Вене. При этом не всегда точно интерпретируется сама ситуация, связанная с конкурсом на кафедру².

В архиве Венского университета среди протоколов филологического факультета за 1938-ой год хранится протокол обозначенный как D.Z. 1386 (1937/ 38). Документ представляет собой отчёт комиссии, возглавляемой деканом факультета, профессором Виктором Христианом (Victor Christian) о самом конкурсе и о результатах голосования. Конкурс касался двух должностей: ординарного профессора кафедры славянского языкознания и экстра-ординарного профессора кафедры славянской филологии и древностей (Lehrkanzel für slawische Philologie und Altertumskunde). По существующим правилам для обеих вакансий было обрано по три кандидата, причём порядок их представления соот-

${ }^{1}$ О нём только вскользь упоминает Вернер Кортхаазе в своей биографии Д. Чижевского. См.: Вернер Кортхаазе, Дмитрий Чижевский: жизнь великого учёного, Siedlce 2009 (Colloquia Litteraria Sedlcensia, red. R. Mnich, volume IV).

${ }^{2}$ Ср. в этом плане замечание В. Янцена: „После смерти Н. С. Трубецкого Чижевский был одним из кандидатов на занятие его кафедры в Вене, но из-за «опороченности еврейскими родственными связями» не получил разрешения на ведение переговоров с Венским университетом от Прусского министерства высшего образования“ (Янцен В. Письма Н. Трубеикого к Д. Чижевскому, в: Dmytro Czyżewski a kultura europejska. Studia pod redakcją Wernera Korthaase i Romana Mnicha (Colloqua Litteraria Sedlcensia, III), Siedlce 2008). Найденные материалы в архиве Венского университета свидетельствуют о том, что Д. Чижевский не только вёл такие переговоры, но и подал официально заявление и все необходимые документы на конкурс. 
ветствовал результатам выбора. На кафедру славянского языкознания предлагались: на первом месте - Райнхольд Траутманн (Reinhold Trautmann), на втором - Фердинанд Ливер (Ferdinand Liewehr), на третьем - Эрвин Кошмидер (Erwin Koschmieder). Соответственно на кафедру славянской филологии и древностей: на первом месте Рудольф Ягодич (Rudolf Jagoditsch), на втором Максимилиан Браун (Maximilian Braun) и на третьем - Дмитрий Чижевский (Dmitrij Tschizewskij).

Как видим, кандидатура Дмитрия Чижевского была на последнем месте в списке, поэтому шансов на должность у него было наименьше. Кафедру возглавил после соответствующего решения министерства Рудольф Ягодич. Однако для биографии Д. Чижевского публикуемые документы представляют особый интерес. Во-первых, перед нами подписанные самим Д. Чижевским два авторбиографических документа: собственно автобиография и список публикаций. Во-вторых, из сохранившихся протоколов мы можем судить, как воспринимали в это время в академической среде Д. Чижевского как учёного. Так, весьма интересным предстаёт замечание в протоколе о характере Д. Чижевского, где сказано: „Fachlich sehr gut beschrieben, etwas mystisch veranlagt, politisch einwandfreier Staatenloser“" (см. протокол). Это замечание свидетельствует, что мистическую настроенность Д. Чижевского, так активно проявлявшуюся в последующие годы жизни, например, в виде разговоров с Романом Якобсоном о чёрте за форточкой, заметили ещё перед войной его знакомые и друзья. Добавим, здесь, что список публикаций Д. Чижевского превосходил все предложенные на конкурс и качественно, и количественно. А в сообщении для министерства приводились очень лестные для Д. Чижевского слова из рекомендации профессора Ф. Шпехта (Fr. Specht): „Ich wüsste Ihnen keinen besseren Gelehrten für das Extraordinariat zu nennen als ihn. Die Zahl seiner Schriften und Arbeiten ist Legion, sie sind deutsch und russisch, einige wohl auch tschechisch geschrieben ... Er ist sicherlich der beste Kenner der Geistesgeschichte der Slaven“.

Указанный контекст дополняет наши представления об облике Дмитрия Чижевского, творчество которого сегодня по-новому осмысляется и возвращается читателям и исследователям, славистам в Европе, в России и Украине. В свое время этот энциклопедический учёный был легендарной личностью, по словам Анджея де Винценза признанным „папой“ немецкой славистики ${ }^{3}$. Мнением Дмитрия Чижевского слависты прошлого столетия очень дорожили, его

${ }^{3}$ Cм.: Vincenz A. de Dmytro Czyżewski, Kultura, nr 5/368, Paris 1978, s. 83-92 (,,długoletni ,papież slawistyki niemieckiej“). В этом же аспекте ср. характеристику Д. Чижевского в книге Тадеуша Врублевского о немецкой славистике: ,jeden z najbardziej znanych slawistów zachodnioniemieckich i jednocześnie najbardziej wszechstronnych, obejmujący swymi zainteresowaniami i pracami szeroki krąg zagadnień życia duchowego Słowiańszczyzny“ (Wróblewski T. S. Slawistyka w NRD $i$ w NRF na tle jej historycznego rozwoju, Poznań 1973, s. 29). 
рецензий и критических выступлений порою просто боялись. Д. Чижевский принадлежал к тем литературоведам 20-ого века, которые по-особому интерпретировали и оценивали наследие прошлого, и для которых каждая эпоха европейской культуры обладала своей неповторимой аурой. Именно в этом смысле Д. Чижевский открывал и изучал памятники европейского барокко, соединяя при этом немецкую педантичность в работе с текстами и новейшие веяния в немецкой филологической и философской мысли. Уже сам перечень монографических исследований Дмитрия Чижевского, появившихся в виде отдельных книг, свидетельствует о незаурядности таланта и работоспособности этого ученого: „История украинской философии“, „История литературы Киевской Руси“, „История украинской литературы“, „Гегель в России“, два тома „Сравнительной истории славянских литератур“, два тома „Истории русской литературы 19-ого века“, два тома „Духовной истории России“, „Философия Григория Сковороды“, а кроме того - сотни и сотни статей на самые разные философские и литературоведческие темы, рецензии, комментарии. Тематика интересов Дмитрия Чижевского объединяет очень широкий круг проблем: от астрономии и астрологии до этики и эстетики, философии тождества, теории литературных влияний, общих проблем поэтического языка.

Отметим, что изучение огромных архивных собраний Дмитрия Чижевского, его библиотек в Галле, в Гейдельберге, как и научное изучение биографии Чижевского, его связей с широким контекстом европейской культуры (от античности до 20-ого века), его связи с такими философами и литературоведами, как Семен Франк, Мартин Хайдеггер, Ханс-Георг Гадамер, Эрнст Кассирер ${ }^{4}$, Карл Ясперс, Роман Якобсон, Федор Степун и сотни других сейчас только начинается ${ }^{5}$.

Публикуемые документы интересны и тем, что хранят дух и символику того времени, указания на членство партии кандидатов на должности (получивший кафедру Р. Ягодич был членом партии с 1938-ого года, возможно, вступив в неё именно из-за должности ${ }^{6}$ ). В этом смысле представленные протоколы не

${ }^{4}$ Cм.: Roman Mnich Ernst Cassirer and Dmytro Chyzhevsky: An Instance of Cassirer's Reception among the Slavs, in: Journal of Ukrainian Studies (2007), Volume 32, Number 2, p. 21-32.

5 См. в этом плане: Д. И. Чижевский Избранное в трех томах. Том 1. Материальк к биографии (1894-1977), Москва 2007. Насколько трудными оказываются тексты Д. Чижевского как философа и филолога для современного восприятия, свидетельствует очёнь неудачное издание четырёх томов его сочинений в Украине. См. мою рецензию: Р. Мних, Wer wird nicht Cyževśkyj ehren? (Чижевський Д. Філософські твори у 4-х тт. Під загальною ред. В. Лісового, Київ: Смолоскип, 2005), в: Україна модерна. Число 12, 2007 (1), Київ - Львів 2007, с. 229-238.

${ }^{6}$ Подробнее о судьбе Рудольфа Ягодича (в частности о его воспоминаниях о Н. Трубецком) см. в комментариях Ф. Полякова в книге: Nikolaj S. Trubetzkoy. RusslandEuropa - Eurasien. Ausgewählte Schriften zur Kulturwissenschaft. Fedor B. Poljakov (Hg.); Redaktion und Vorwort von Heinz Miklas. Wien 2005, S. 405-410. 
только рассказывают о судьбе Д. Чижевского, но и составляют дополнительную страницу в истории славистики Венского университетата ${ }^{7}$.

Для настоящей публикации избранны следующие документы (подписи и символика сканированы): 1) протокол заседания; 2) автобиография Д. Чижевского; 3) список публикаций Д. Чижевского; 4) письмо в министерство о результатах заседания; 5) сообщение о кандидатах; 6) объяснительная записка отсутствующего на заседании профессора, представляющая исключительно исторический интерес (в смысле царящей в то время духовной атмосферы).

D.z. 1386 aus $1937 / 38$.

\section{Protofoll}

aufgenommen in Der Defanats̆fanzlei Der philofophifahen Fafultät Der SAniverfität

in Mien am Montag, Den 24.0ktober 1938

um 11 alfr $30 \quad \mathfrak{M}$.

Qunfigenber:

Dekan Prof.Dr.Viktor CHRISTIAN.

Umwejent:

Die Unterzeichneten.

Gegenftand:

Wiederbesetzung der Lehrkanzel fur slawische Philologie und Altertumskunde.

Guresentititiste:

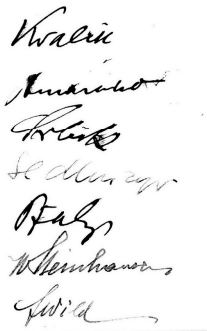

${ }^{7}$ См. общий обзор Slawistik an der Universität Wien. Vorwort von Heinz Miklas (Wien 1999) и библиографию (ibidem, S. 9-13). 
P r o t o k o 11 ,

aufgenommen in der Kommissionssitzung über Wiederbesetzung der

Lehrkanzel für slawische Philologie und Altertumskunde am 24. Oktober 1938.

Anwesend die Prof. Egger, Havers, Kralik, Marchet, Pfalz, Sedlmayr, Srbik, Steinhauser, Wild, Pd. Dworzak.

Beginn 12 Uhr 35.

$\underline{\text { Havers }}$ Vor dem Kriege bestanden 2 Ordinariate für slawische Sprachwissenschaft in Wien, bis 1923 waren sie beide vakant, dann wurde eines mit Trubetzkoy besetzt. Erwünscht wäre die Besetzung eines Ordinariates und daneben die eines Extraordinariates.

Marchet Es besteht eine Weisung, dass vorläufig keine Professoren der Prager deutschen Universität in die Vorschläge aufgenommen werden sollen, was natürlich einen Verlust für die Vorschläge bedeuten kann.

Havers beginnt nun die Aufzählung der Kandidaten.

Max Fassmer 1886 in Petersburg geboren, jetzt in Berlin, ist nicht sehr gut beschrieben und will selbst nicht kommen.

Reinhard Trautmann, seit 1926 o.Prof, Leipzig, besitzt gute sprachwissenschaftliche Kenntnisse, beherrscht auch das Litauische, ist den anderen weit überlegen. Danach wären zu nennen:

K.H.Meyer, Königsberg, die Gutachten lauten jedoch nicht sehr vorteilhaft.

Paul Diels ist schwerhörig und daher in Ausübung seiner Tätigkeit stark behindert.

Erwin Koschmieder, Wilna besitzt viele lebendige Beziehungen zu den slawischen Sprachen der Gegenwart.

Johannes Lohmann, seit 1933 Dozent in Freiburg (Breisgau) und auch in Basel; kann sehr viele Sprachen und nimmt dadurch eine besondere Stellung in der Sprachwissenschaft ein.

Berndt v. Arnim geb. 1899 Rostock kann auf Studienreisen in Bulgarien hinweisen, schrieb über slawische Himmelskunde; er soll ehrlich und offen sein.

Simon Pirchecker, Bonn hat wenige Arbeiten und wenige Beziehungen zu lebenden Sprachen; er wäre vielleicht besser in Graz am Platz, zumal er sich gerade mit der slowenischen Sprache hauptsächlich befasst.

Für das Extraordinariat wären zu nennen:

Josef Mattl, Graz, dürfte aus politischen Gründen nicht in Betracht kommen.

Jagoditsch habil. Wien 1932; neben diesen an zweiter Stelle:

Max Braun, Göttingen habil. seit 1936 (8 Veröffentlichungen), geb. in Petersburg. Mitrie Tschizewskij (Ukrainer), war 1927 Prof. an der ukrain. Univers. in Prag. Seit 1932 Titel eines a.o.Prof., in Halle tätig. Fachlich sehr gut beschrieben, etwas mystisch veranlagt, politisch einwandfreier Staatenloser. 7 Bücher, 58 Aufsätze.

Hans Halm, geb. 1887 in Trautenau hat große Verdienste aus der Zeit seiner Kriegsgefangenschaft in Sibirien. Er war angeblich 1919 in Irkutsk habilitiert. Hielt Aufklärungsvorträge über Sowjet-Russland. Er wäre vielleicht gewisser Unterstützung würdig, soll aber für die Lehrkanzel nicht genannt werden.

Marchet stimmt einer Nennung Trautmanns zu, Vassmer, Mattl sind abzulehnen; die Frage Halms Stipendium ist noch in Schwebe und politisch ungeklärt.

Pfalz Man hat es Halm vielfach verübelt, dass er den Irkutsker Prof.-Titel führte.

Dekan Die Vorschläge für das Ordinariat sollen sprachwissenschaftlich sein, für das Extraordinariat literatur- und kulturkundlich.

Srbik bedauert, dass wegen des früher bezüglich Prager Professoren erwähnten Verbotes Ferdinand Liewehr nicht genannt wurde, der durch einen Brief von Vostri ihm sehr gut empfohlen wurde.

Dekan empfiehlt zumindest eine Aufzählung seiner Qualitäten; übrigens erscheint ihm doch die Aufnahme auch in den Vorschlag möglich, da ja Liewehr in Prag nur Assistent ist. 


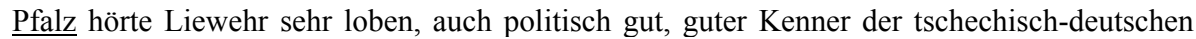
Beziehungen.

Wild fragt über Schneeweiss (Belgrad).

Egger Der Genannte ist Vertreter der Volkskunde.

Havers Vorschlag für das Ordinariat:

1) Trautmann

2) Liewehr (dabei zu betonen, dass er nicht beamteter Prof. ist), Koschmieder

3) Lohmann, Arnim

Kralik Es wäre zu betonen, dass Liewehr für Wien besonders geeignet wäre.

Havers Vorschläge für das Extraordinariat:

1) Jagoditsch

2) Braun

3) Tschizewskij

In einer Aussprache, an der sich Sedlmayr, Pfalz und Egger beteiligten, wird mehrfach betont, wie man auch im Ausland am Balkan, den von uns erhofften Ausbau der slawistischen Institute erwartet. Er könnte ein wichtiger Faktor in unseren Beziehungen zum Balkan sein. Ferner setzen sich die Genannten besonders für Jagoditsch als für das Extraordinariat geeigneten Kandidaten ein, besonders auch wegen seiner Verbundenheit mit dem Balkan, seiner Abstammung aus gemischtsprachiger Gegend im Süden entsprechend. Sedlmayr hebt seine Vertrautheit mit Fragen der byzantinischen Kultur hervor und seine menschlich hervorragenden Eigenschaften.

Bezüglich Halms soll keine Erwähnung konkreter Art gemacht werden, solange der Fall politisch ungeklärt ist.

Schließlich wird in einer anschließenden kurzen Besprechung beschlossen, Dr. Friedrich

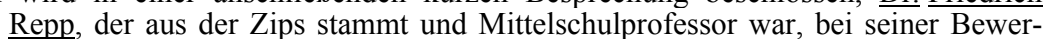
bung um das Lektorat der tschechischen und slowakischen Sprache zu befürworten ist, worüber ein Bericht von Prof. Havers erbeten wird.

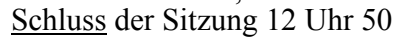

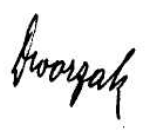

\section{Lebenslauf}

Ich wurde als Sohn des Edelmanns Iwan Tschižewskij (Čyževskyj) und seiner Ehefrau Maria, geb. Erschow, in Alexandria, Gouvernement Cherson (Ukraine) am 23.III.1894 geboren. Ich besuchte das klassische Gymnasium meiner Heimatstadt, bestand 1911 die Reifeprüfung und studierte 1911-13 an der Kaiserlichen Universität St.-Petersburg und 1913-18 an der Universität des heiligen Wladimir in Kiew Philosophie und russische Philologie. Die Staatsprüfung konnte ich erst 1919 bestehen, als Kiew vorübergehend von der sog. „Weißen Armee" besetzt wurde, und der normale Gang des Universitätslebens wiederhergestellt wurde. - Ich habe schon meine Tätigkeit als Dozent an den Kiewer Hochschulen begonnen, als die Verfolgung durch die Sovjets-Obrigkeit mich gezwungen hat, ins Ausland zu gehen. Ich habe mich im WS. 1921/2 an der Ruprecht-Karl-Universität in Heidelberg und SS. 1922 bis WS. 1923/4 an der Albert-Ludwigs-Universität in Freiburg in Breisgau immatrikulieren lassen, wo ich vor allem Philosophie studierte. Den deutschen Dr.-titel habe ich in Halle 1933 erworben (Philos., slav. Philol., Kirchengeschichte; ,summa c. laude“).

1924 wurde ich zum Lektor der Philosophie an dem Ukrainischen Pädagogischen Institut in Prag ernannt, wo ich auf Grund der von mir eingereichten Arbeiten 1925 Dozent und 1927 Professor wurde; 1929 habe ich mich an der Ukrainischen Universität in Prag mit der Arbeit über „Hegel und die französische Revolution“ habilitiert und wurde 1932 zum ao. Professor. Seit 1930 arbeitete ich an der „Deutschen Gesellschaft für slavistische Forschung“ an der Prager Deutschen Universität, in deren Auftrage ich zwei Bände ihrer Veröffentlichungen herausgegeben habe. Seit dem SS. 1932 bin ich als Lektor der Slavistik an der Martin-Luther- 
Universität in Halle a.d.S. und seit dem SS. 1935 auch an der Friedrich-Schiller-Universität in Jena tätig.

Außer den Sprachkursen (russisch, ukrainisch, polnisch, tschechisch und slovakisch) habe ich unt. and. folgende Vorlesungen an den beiden Universitäten Halle und Jena gehalten:

Geschichte der alten russischen Literatur,

Geschichte der neueren russischen Literatur,

Deutsche Philosophie und deutsche Dichtung in Russland,

Einfluss des Krieges und der Revolution auf die russ. Sprache,

Einführung in das Studium der slavischen Sprachen (Grundlage der vergl. Grammatik der slav. Sprachen),

Altkirchenslavisch,

Ukraine: Land, Bevölkerung, Kulturgeschichte,

Polnische Kulturgeschichte,

Slavische Mystiker,

Geistige Strömungen in Russland im 18. und 19. JJ.,

Ostslavische Volkskunde,

Deutsche Einflüsse im Geistesleben der Slaven seit d. 17. J.,

Altrussische Hagiographie,

Geschichte des Protestantismus bei den Slaven usf.

Außer der schon stattgefundenen Promotionen meiner Schüler in der Slavistik als Nebenfach, sind jetzt drei Doktordissertationen, die von mir angeregt und geleitet worden sind, abgeschlossen („Die Predigt“ des ,Geistigen Abendmahls' von Simeon Polockij -1683 - vom literarischen Standpunkt aus beurteilt“, „Die ,ukrainischen Novellen“ von N. V. Gogol'“ und „Die Nacht in der Dichtung der polnischen Romantik“ - Veröffentlichungen meiner Hallenser Schüler - in der „Zeitschrift für slavische Philologie“ und „Germanoslavica“ seit 1935 (A. Dauenhauer, D. Gerhardt, A. Hoppe).

Halle a.d.

Dmitrij Tschižewskij (Čyževskyj)

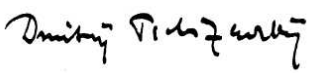

Die wissenschaftlichen Veröffentlichungen von D. Tschižewskij

(nur die wichtigsten Arbeiten sind berücksichtigt, die fachphilosophischen Arbeiten sind meist außer Acht gelassen).

Als Einzelveröffentlichungen erschienen:

1. Logik (ukrainisch). Prag. 1924. S. 332.

2. Griechische Philosophie vor Plato. (ukrainisch). Prag. 1927. XXIV +306.

3. Philosophie in der Ukraine. Versuch einer Quellenkunde. (ukrainisch). Prag.1925. S. 200; 2. Ausgabe, I Teil. Prag. 1929. S. 144.

4. Abriss einer Geschichte der Philosophie in der Ukraine. (ukrainisch). Prag. 1931. S. 176.

5. Die Philosophie von H. S. Skovoroda. (ukrainisch). Warschau. 1934. S. 224.

6. Einige Quellen der Symbolik von H. S. Skovoroda (ukrainisch). Prag. 1934. S. 22.

7. Hegel in Russland. Reichenberg i. B. 1934. S. 240 (enthalten in der von mir herausgegebenen Sammelschrift „Hegel bei den Slaven“. Reichenberg i. B. 1934. S. 494).

Als Aufsätze:

8. Die abendländische Philosophie in der alten Ukraine. „Abhandlungen des Ukrainischen Wissenschaftlichen Institutes in Berlin“, I (1928), 71-89.

9. Tjutčev und die deutsche Romantik. „Zeitschrift f. slavische Philologie“, IV (1928), 299 323.

10. Hegel et Nietzsche. „Revue d'Histoire de la Philosophie“. III (1929). S. 321-347.

11. Schiller und die „Brüder Karamazov“. „Zeitschrift f. slav. Philologie“ VI (1929), 1-42.

12. Zum Problem des Doppelgängers (russisch). „Von Dostojevskij. Sammelschrift"“. Prag. I (1929), 9-38. 
13. H. S. Skovoroda und die deutsche Mystik (russisch). „Abhandlungen der Russischen Volksuniversität in Prag“, II (1929), 283-301.

14. Hegel und die französische Revolution (ukrainisch). „Abhandlungen des Ukrainischen Pädagogischen Institutes in Prag", I (1929), 469-504.

15. Renaissance und das ukrainische Geistesleben. „Abhandlungen des Ukrainischen Wissenschaftlichen Institutes in Berlin“, II (1929), 52-55.

16. Die philosophische Methode Skovorodas. „Abhandlungen der Ševčenko-Gesellschaft in Lemberg" (ukrainisch), Bd. 99, 145-171.

17. Hegel bei den slavischen Völkern. „Verhandlungen des ersten Hegelkongresses in Haag“. $1930,127-145$.

18. Skovoroda-Studien. I. Skovoroda und Angelus Silesius. „Zeitschrift für slav. Philologie“, VII (1930), 1-33.

dasselbe, II. Skovorodas Erkenntnis-Lehre und Philo. Ebendort. X (1933), 47-60.

dasselbe, III. Skovorodas Bibelinterpretation im Lichte der kirchenväterlichen und der mystischen Tradition.

dasselbe, IV. Skovoroda und Valentin Weigel. Ebendort. XII (1935)......

19. Zur Frage über die Pflanze als religiöses Symbol. „Actes du V. congres International d'Histoire des Religions". Lund. 1930...

20. Hegel et la revolution française. „Second congres polonais philosophie“. Warschau. 1930, $45-48$.

21. Zum Doppelgängerproblem bei Dostojevskij; in den von mir herausgebenden „Dostojevskij-Studien“. Reichenberg i. Böhmen. 1931, 19-50 (und einzeln).

22. Folkloristisches zu Dostojevskij (dortselbst, 113-6).

23. Goljadkin-Stavrogin bei Dostojevskij. „Zeitschrift f. slav. Philologie“, VII (1931), 358362.

24. Plato im alten Rußland. „Memoiren der russischen historischen Vereins in Prag“, II (1931), 71-81.

25. Dostojevskij-Psychologe (tschechisch). Sammelschrift „Dostojevskij“. Prag. 1931, 25-41.

26. Zur Charakterologie der Slaven. Ukrainer. ,Slavische Rundschau“. 1931, IV, 237-244.

27. Dostojevskij und die westeuropäische Philosophie (kroatisch). „Nova Evropa“ (Zagreb), 1931, 4, 232-238.

28. Phonologie und Psychologie. „Travaux du Cercle linguistique de Prague“, IV (1931), 322.

29. Literarische Lesefrüchte. Nrr. 1-5. „Zeitschrift f. slav. Philologie“, VIII (1931), 48-54.

dasselbe. II, Nrr. 5-15. Dortselbst. X (1933), 380-401.

dasselbe. III, Nrr. 16-26. Dortselbst. XI (1934), 21-34.

dasselbe. IV, Nrr. 27-41. Dortselbst. XIII (1936), 51-76.

dasselbe. V, Nrr. 42-48. Dortselbst. XIV (1937), 331-354.

dasselbe. VI, Nrr. 49-53. Dortselbst. XV (1938), 105-117.

30. Ševčenko und D. F. Strauß. ,Zeitschrift f. slavische Philologie“, VIII (1931), 368-387.

31. Aus der Geschichte der russischen Sprachphilosophie. „Charisteria für V. Mathesius“. Prag. 1932. 18-20.

32. Aus Sturs Nachlass. „Slavische Rundschau“, 1932, 5, 432-4.

33. P.O. Kuliš, ein ukrainischer Philosoph des Herzens. „Orient und Occident“, XIV (1935), $7-18$.

34. Neue Veröffentlichungen über die čechische Barockdichtung. „Zeitschrift f. slavische Philologie“, XI, 426-432; XII, 183-191; XV, 140-155.

35. Das „Wahre Christentum“ J. Chr. Arndts in Russland. „Evangelium und Osten“ (Riga). 1935, 41-47 (Heft 3).

36. J. Böhme in Rußland. Ebendort. 1935, 10, 175-184; 11, 200-205.

37. Neue Comenius-Funde. ,Zeitschrift f. slav. Philologie“, XII (1935), 11 bis 183.

38. Studenten aus der Slovakei in Halle. „Sbornik Matice Slovenskej“'II, XIII (1935), 3, 203 6.

39. Ukrainische Drucke im XVIII. J. in Deutschland (ukrainisch). „Naša kultura“. Warschau. 1936, I, 1-12; III, 181-187.

40. Wesen und Aufgaben der tschechoslowakischen Philosophiegeschichte. „Slawische Rundschau“, 1936, I, 13-22; II, 68-80. 
41. Zum Unsterblichkeitsproblem bei Dostojevskij. „Leben und Tod. Sammelschrift“ (russisch). Prag. II, 26-38.

42. Tobias Gottfried Schröer a Slovensko (slovakisch). „Slovenske Pohl'ady“, 1936, 140-6.

43. $\mathrm{Zu}$ den altrussischen Längebezeichnungen. „Indogermanische Forschungen“, LIV, 2 (1936), 122-124.

44. Sevčenko und Religion (ukrainisch). Begleitartikel im Bd. X. der Ševčenkos Gesammelten Werke. Warschau, 1936, 329-347.

45. Beitrag zur Symbolik der tschechischen religiösen Dichtung (tschechisch). „Slovo a slovesnost“. Prag. 1936, 2, 98-105.

46. Zwei Briefe Ludovit Sturs an A. P. Pott. „Sbornik Matice Slovenskej“, I, XIV (1936), 1, $184-187$.

47. Puškin und die Romantik. „Slavische Rundschau“, 1937, 2, 69-80.

48. Puškin zwischen der Romantik und dem Klassizismus (slovakisch), „Slovenske Pohl'ady“, 1937, I, 36-41; II, 75-83.

49. Zur Komposition von Gogol's „Mantel“. „Zeitschrift f. slavische Philologie“. XIV (1937), 63-94.

50. Bemerkungen zur Dichtung Skovorodas. „Festschrift f. Prof. I. Ohienko“ (ukrainisch). Warschau. 1937, 172-189.

51. Zu einem Gedicht Tjutčevs. ,Zeitschrift f. slavische Philologie“, II (1937), 325-331.

52. Analecta Comeniana. I. „Kyrios“ (Breslau), II (1938), 4, 313-330.

53. Briefwechsel O. Bodjanskijs mit dem čechoslovakischen Verein in Preßburg. „Sbornik Matice Slovenskej“. I. XIV (1937), 168-171.

54. Zwei neue Funde aus dem Werk des Comenius (tschechisch). „Slovo a slovesnost“, III (1937), 4, 230-2.

55. Die russischen Drucke der Hallenser Pietisten. „Kyrios“, III (1938), 1/2, 56-74.

56. Ein unbekannter Hallenser slavischer Druck. „Zeitschrift f. slav. Philologie“. XV (1938), 76-80.

57. Neue Veröffentlichungen über die slowakische Geistesgeschichte. „Zeitschrift f. slavische Philologie“, XV (1938), 155-169.

58. Ein Brief von August Cieszkowski an A. F. Pott. „Zeitschrift f. slav. Philologie“. XV (als Einzeldruck, erscheint im Heft 3/4).

Besprechungen in den folgenden Zeitschriften:

„Zeitschrift für slavische Philologie“,

„Slavische Rundschau“,

"Germanoslavica“,

"Zeitschrift f. osteuropäische Geschichte“,

„Kyrios“",

„Zeitschrift f. Kirchengeschichte“,

„Jomsburg“,

„Archiv f. Geschichte der Philosophie“,

„Deutsche Literaturzeitung“" usf.

Die Sprache der erwähnten Arbeiten ist, wenn es nicht anders vermerkt, die deutsche (NNr. 10. und 20-die französische).

Zahl: 1386 aus 1937/38.

Wien, am 12. November 1938.

An

das Ministerium für innere und kulturelle Angelegenheiten.

Abt. IV, Erziehung, Kultus und Volksbildung

in

$\underline{\text { Wien }}$

Ich lege hiermit den Bericht einer Kommissionssitzung vor, die am 24. Oktober 1938 unter meinem Vorsitz in Anwesenheit der Herren Dworzak, Egger, Hassinger, Havers, Hirsch, Knoll, Marchet, Kralik, Pfalz, Sedlmayr, Srbik, Steinhauer und Wild stattfand und die Besetzung der nach Prof. Trubetzkoy freigewordenen Lehrkanzel für slawische Philologie 
und Altertumskunde zum Gegenstand hatte. Auf Grund dieser Beratung erstattete Prof. Havers in der Fakultäts-Sitzung am 5. November 1938 seinen Bericht, der folgende Organisations- und Besetzungsvorschläge enthält.

In Anbetracht der Wichtigkeit, die dem Studium der slawischen Sprachen und Kulturen gerade in Wien zukommt, wird gebeten, an der Wiener Universität eine ordentliche Professur für slawische Sprachwissenschaft und eine außerordentliche Professur für slawische Literatur und Kulturkunde einzurichten. Es würde damit nur der bis 1921 vorhandene Bestand an zwei ordentlichen Lehrkanzeln für slawische Philologie einigermaßen wiederhergestellt.

Zur Besetzung der beiden Lehrkanzeln werden folgende Vorschläge erstattet;

a) ordentliche Professur für slawische Sprachwissenschaft: an erster Stelle: Reinhold T r a u t m a $\mathrm{n} n$, o. Prof. a. d. Univ. Leipzig, an zweiter Stelle: Ferdinand L i e w e h r, tit. a. o. Prof. a. d. Univ. in Prag und

Erwin K o s c h m i e d e r, o. Prof. a. d. Univ. in Wilna,

an dritter Stelle: Bernd von A r n i m , Pd. d. Univ. in Berlin.

b) außerordentliche Professur für slawische Literatur und Kulturkunde: an erster Stelle: Rudolf J a g o d i t s c h , Pd. a. d. Univ. Wien, an zweiter Stelle: Maximilian B r a u n, nichtbeam. a. o. Prof. a. d. Univ. in Göttingen,

an der dritten Stelle: Dimitrij T s c h i z e w s k i j, Lektor für slawische Sprachen a. d. Univ. Halle und Jena.

Ich bitte im Sinne dieser Vorschläge die Besetzung einer ordentlichen und einer außerordentlichen Professur für Slawistik an der Universität in Wien zu beantragen. Für das neu angesprochene Extraordinariat steht eine Stelle für Verfügung, da laut Mitteilung des Reichserziehungsministeriums derzeit nicht geplant ist, die a. o. Professur für theoretische Physik, die Prof. Kottler innehatte, zu besetzen. Uber die weltanschauliche und politische Eignung der vorgeschlagenen Gelehrten liegen bisher nur zum Teil Auskünfte vor, insbesondere konnte über Tschizewskij, Halle, noch nichts Genaueres erhoben werden.

Der kommissarische Dekan:

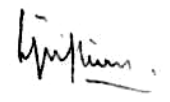

\section{BERICHT \\ über die Kommissionssitzung betreffend Wiederbesetzung der Lehrkanzel für slawische Philologie u. Altertumskunde,}

die am Montag, den 24. Oktober 1938 um 11.30 Uhr vormittags unter dem Vorsitze Sr. Spektabilität, des Herrn Dekans Prof. Dr. CHRISTIAN stattfand und an der teilnahmen die Herren: Egger, Hassinger, Havers, Hirsch, Knoll, Marchet, Kralik, Pfalz, Sedlmayr, Srbik, Steinhauser, Wild, Winkler, Dvorzak als Schriftführer.

Der Lehrstuhl für slawische Philologie an der Universität in Wien hat eine ruhmreiche Vergangenheit; ich brauche nur an die klangvollen Namen Franz von Miklosic, Jagic, Rešetar und Vondrak zu erinnern; auch der letzte Inhaber der Wiener Lehrkanzel, Nikolai Trubetzkoj, hat sich nicht nur als Philologe, sondern auch als Sprachforscher, speziell als Phonologe, einen großen Namen erworben. Es ist nicht leicht, einen Nachfolger zu finden, der dieser großen Männer würdig ist.

Vor dem Kriege bestanden an der Wiener Universität für das Fach der Slawischen Philologie zwei Ordinariate, welche in der letzten Zeit durch die Professoren Dr. Milan Rešetar (Kroate) und Dr. Wenzel Vondrak (Tscheche) vertreten waren.

Im Jahre 1919 gab Rešetar seinen Wiener Lehrstuhl freiwillig auf, um an die Agramer Universität zu übersiedeln, zwei Jahre später tat Vondrak dasselbe und ging an die neube- 
gründete tschechische Universität in Brünn. Bis zum Jahre 1923 blieben beide Lehrstühle vakant. Im Sommer 1923 wurde Professor Dr. Nikolaus Trubetzkoy an die Wiener Universität berufen. Der zweite Lehrstuhl für slawische Philologie wurde seither nicht mehr besetzt, aber auch nicht vom Stellenplan der philosophischen Fakultät gestrichen.

Es ist daher wohl keine unbillige Forderung, wenn die Fakultät beantragt, dass neben dem Ordinariat für slawische Philologie mit sprachwissenschaftlicher Ausrichtung auch ein Extraordinariat für slawische Literatur und Kulturkunde errichtet werden soll.

Was zunächst das Ordinariat betrifft, so wäre eine ideale Besetzung gegeben durch die Person des Berliner Ordinarius Max VASMER, geb. 1886 in Petersburg. Vasmer hat vor allen anderen den großen Vorzog, dass er im slawischen Lande geboren ist und daher von vorneherein Dinge mitbringt, die sich ein anderer nur schwer oder gar nicht mehr aneignen kann. Neben dem Slawischen kann er auch Neugriechisch, Albanisch, Finnisch, Estnisch u.s.w. Dadurch steht er Trubetskoj besonders nahe; außerdem ist er ein ausgezeichneter Organisator.

Aber abgesehen davon, dass er von der Partei nicht besonders günstig beurteilt wird, kann er sich auch, wie er schreibt, kaum entschließen, Berlin mit Wien zu vertauschen.

Nach dem Ausscheiden Vasmers bleibt für den Vorschlag an 1. Stelle zweifellos nur einer übrig, nämlich der Leipziger Ordinarius Reinhold TRAUTMANN, geb. 16.I.1883 in Königsberg (für Vita und Schriftenverzeichnis siehe Beilage 1). Alle über Trautmann abgegebenen Gutachten stimmen darin überein, dass er den anderen Slawisten weit überlegen ist. Er hat besonders gute sprachwissenschaftliche Arbeiten aufzuweisen: sein baltisch-slawisches Wörterbuch (1923) ist geradezu ein Meisterstück; auch seine ,altpreußischen Sprachdenkmäler“ (1909) und sein Werk über die altpreußischen Personennamen (1925) sind sauber gearbeitet und unbedingt zuverlässig. Weniger originell sind seine literaturhistorischen Bücher über die Nestorische Chronik (1931) und die Volksdichtung der Großrussen (1935), aber auch sie sind solide Leistungen. Was für uns besonders ins Gewicht fällt, ist der Umstand, dass Trautmann auch das Litauische beherrscht und nach dem Ausscheiden von Hofrat J o k 1, der bisher die Vorlesungen über diese hochaltertümliche und wichtige indogermanische Sprache gehalten hat, wäre es sehr zu begrüßen, einen Slawisten zu gewinnen, der auch diese Vorlesungen übernehmen kann.

Von der Partei liegen günstige Urteile über Trautmann vor.

2.) An zweiter Stelle nennt die Kommission den nicht beamteten außerordentlichen Professor für slawische Philologie an der Universität Prag, Ferdinand L i e w e h r , geb. am 22.XI.1896 in Seitendorf bei Fulnek (Mähren). Er wurde 1924 zum Dr. phil. in Prag promoviert, habilitierte sich daselbst 1929 und wurde 1937 zum Extraordinarius ernannt. Zum Assistent am Slawischen Seminar wurde er 1924 ernannt und 1926 zum Lektor für tschechische Sprache. Trotzdem er so vielseitig in Anspruch genommen ist, hat er sich doch die Zeit abgerungen, zu einer Reihe tüchtiger Arbeiten, die bei der Fachwelt sehr gute Aufnahme fanden. Wir nennen besonders die Schrift „Die Ortsnamen des Kuhländchens“ (1926 Reichenberg), „Zur Chronologie des serbokroatischen Akzents“ (Prag 1927), „Einführung in die historische Grammatik der tschechischen Sprache“ (Brünn 1933). Der Umstand, dass Liewehr als ausgezeichneter Kenner der Ortsnamenforschung gilt, macht ihn für Wien ganz besonders geeignet und die hiesigen Germanisten, besonders Pfalz und Steinhauser, würden es sehr begrüßen, in ihm einen Mitarbeiter zu finden.

Als Mensch ist Liewehr ein ehrlicher, offener Charakter, sein starkes Pflichtbewusstsein, ist einer der vornehmsten Züge in seiner auch sonst durchaus deutschen Wesensart. Nicht ohne Grund stellt sein Name auch auf der Münchner Liste.

Ebenfalls an zweiter Stelle schlägt die Kommission vor Erwin K o s c h m i e d e r , Ordinarius für slawische Philologie an der Universität Wilna; Lebenslauf und Schriftenverzeichnis siehe in Beilage 2. Wie Koschmieder in einem Schreiben vom 20.10.1938 mitteilt, hat sich schon das Bayrische Ministerium an ihn mit der Anfrage gewandt, ob er Bernekers Lehrstuhl in München übernehmen möchte. Koschmieder hat bereits in München zugesagt. „Sollten sich aber", so schreibt er, ,irgendwelche Schwierigkeiten ergeben, oder sollten irgendwelche Gesichtspunkte es wünschenswert erscheinen lassen, würde ich natürlich sehr gern nach Wien kommen. Abgesehen von anderen Dingen zieht mich nach Wien 1.) das dortige Zentrum der syntaktischen Forschungen und 2.) die Wiener Leistungen in der Geschichte des byzantinischen Kirchengesanges. Meine politische Einstellung ist nationalsozialistisch schon seit vielen Jahren“. 
3.) An dritter Stelle nennt die Kommission den Berliner Privatdozenten Dr. Bernd von A r n i m, Sohn des früheren Ordinarius für klassische Philologie an der Universität Wien. Lebenslauf und Schriftenverzeichnis siehe in Beilage 3. Von Arnim hat eine gute indogermanische und slawische Vorbildung genossen an der Universität München, Frankfurt a.M., Wien und Leiden, wo er Schüler des bekannten Slawisten Prof. Dr. Nr. von Wijk war. Er hat eine ausgezeichnete Arbeit über das Psalterium Sinaiticum geschrieben (1930), dessen Sprache er genau grammatisch dargestellt hat. Aus verschiedenen Aufsätzen in Vasmer's Zeitschrift ersieht man, dass er eine nicht geringe etymologische Begabung hat, und sie lassen auch Kenntnisse in nicht-indogermanischen Sprachen erkennen. Sehr lesenswert sind auch seine „Beiträge zum Studium der altbulgarischen und altkirchenslawischen Wortbildung und Übersetzungskunst" (1931). Augenblicklich arbeitet er an einer umfassenden Studie über slawische volkstümliche Sternnamen, die reiche Ergebnisse verspricht. Als Mensch ist von Arnim ein durchaus ehrlicher Charakter, unbedingt staatstreu und politisch einwandfrei, um seine Kinder als gute Deutsche erziehen zu können, kehrte er unter schweren Opfern aus dem Ausland zurück.

Für das neu zu errichtende Extraordinariat nennt die Kommission an erster Stelle Dr. Rudolf J a g o d i t s c h, Dozent für slawische Philologie an der Universität Wien, geb. 1892 in Graz, Kriegsteilnehmer, 1915 in russische Gefangenschaft geraten, zwei vergebliche Fluchtversuche, ein dritter gelungener Fluchtversuch führte ihn 1920 wieder in die Heimat zurück. Er studierte dann slawische Sprachwissenschaft, Kulturgeschichte der slawischen Völker und osteuropäische Geschichte bei Trubetzkoj, Übersberger und Patsch. Nachdem er die Rigorosen in allen genannten Fächern mit Auszeichnung bestanden hatte, wurde er 1927 zum Doktor phil. promoviert. Es folgte ein 2 1/2 jähriger Aufenthalt an der österreichischen Gesandtschaft in Moskau, wodurch er die Möglichkeit bekam, an einem der wichtigsten Punkte der slawischen Welt seine Studien fortzusetzen und zu vertiefen. Die Frucht seines Moskauer Aufenthaltes war das Buch „Das Leben des Protopopen Auwakum“, Berlin 1930, das in Fachkreisen eine günstige Aufnahme fand. Im März 1932 habilitierte er sich an der Leipziger Universität für das Gesamte Fach der slawischen Philologie, auf den Rat von Trubetzkoj beschränkt er sich aber auf Vorlesungen und Übungen größtenteils auf dem Gebiete der Literatur und Kulturgeschichte, vgl. das ausführliche „Curriculum vitae“ in Beilage 4. Ein Verzeichnis seiner Vorlesungen, seiner wissenschaftlichen Publikation, seiner Aufsätze in Tageszeitungen, seiner Studienreisen in slawischen Ländern u.s.w. liegt bei.

Jagoditsch ist seit 1938 Mitglied der Partei, vorher gehörte er schon dem HS-Lehrerbund an. Er ist verheiratet und Vater eines Kindes. Die Kommission ist der Ansicht, dass gerade Jagoditsch durch seine Kenntnisse und Fähigkeiten für das Wiener Extra-Ordinariat ausgewiesen ist.

An zweiter Stelle schlägt die Kommission vor den Göttinger Extraordinarius Dr. Maximilian B r a u n, Sohn russischer (arischer) Eltern und nach dem frühen Tode dieser Eltern von seinem Stiefvater, Prof. Dr. Friedrich Braun in Leipzig erzogen, vgl. seinen Lebenslauf in Beilage 5. Braun hat besonders auf südslawischem Gebiet gearbeitet und hier vor allem über Kulturgeschichte und Volksdichtung. Er ist ein ausgezeichneter Lehrer, der seine Schüler zu packen weiß, großes pädagogisches Geschick verrät auch die Wahl der Themen zu seinen Vorlesungen und Übungen (Siehe Beilage Nr. 5). Aus dem Verzeichnis seiner Veröffentlichungen sei besonders genannt die Nr. 7 - Beobachtungen zur Frage der Mehrsprachigkeit (GGA 199/4), die beweist, dass er auch der Frage der allgemeinen Sprachwissenschaft sein Interesse zugewandt hat.

Er ist Mitglied der Partei.

3.) Dimitrij T s c h i z e w s k i j, augenblicklich Lektor der Slawistik in Halle und Jena, ist geborener Ukrainer, Sohn eines russischen Generals, studierte 1911-19 in Petersburg und Kiew, dann an der deutschen Universität Heidelberg und Freiburg (Breisgau). Den deutschen Doktortitel hat er 1933 in Halle erworben. 1924 wurde er zum Lektor der Philosophie an dem Ukrainischen Pädagogischen Institut in Prag ernannt, wo er auf Grund der von ihm eingereichten Arbeiten 1925 Dozent und 1927 Professor wurde; 1929 hat er sich an der ukrainischen Universität in Prag habilitiert mit der Arbeit über „Hegel und die französische Revolution“, wo er 1932 zum a. o. Professor ernannt wurde. Seit 1930 arbeitete er an der „Deutschen Gesellschaft für slawische Forschung" an der Prager deutschen Universität, in deren Auftrag er 2 Bände ihrer Veröffentlichungen herausgab. Seit 1932 ist er Lektor in Halle und 
Jena, vgl. seinen Lebenslauf und sein Schriftenverzeichnis in Beilage 6. Der frühere Vertreter der Sprachwissenschaft an der Universität Halle, Prof. Dr. Fr. S p e c h t (Jetzt Breslau) stellt ihm ein außerordentlich gutes Zeugnis aus. „Ich wüsste Ihnen keinen besseren Gelehrten für das Extraordinariat zu nennen als ihn. Die Zahl seiner Schriften und Arbeiten ist Legion, sie sind deutsch und russisch, einige wohl auch tschechisch geschrieben...... Er ist sicherlich der beste Kenner der Geistesgeschichte der Slaven....... Politisch ist er als „Staatenloser“ völlig einwandfrei.“

Wien, den 28. Oktober 1938
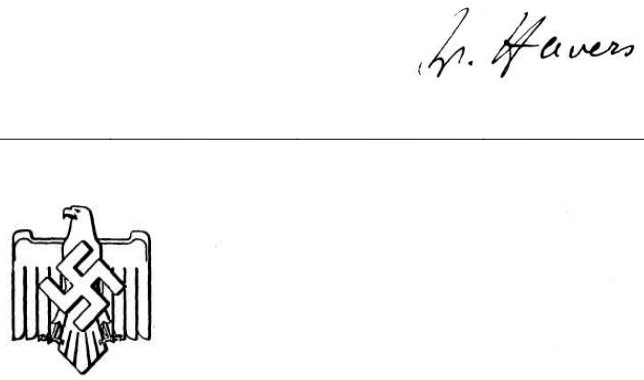

\title{
DER STELLVERTRETER DES VERBANDSFÜHRERS
}

DES DBUTSCHEN GOLF VERBANDES IM DEUTSCHEN REICHSBUND FUR LEIBESUBUNGBN

FUR DEN GAU XVII (DEUTSCHOSTERREICH)

\author{
WIBN II/1, PRATER-KRIEAU, \\ TBLBFON: R $45-0-40$
}

19. Okt.1938.

Ew. Spektabilität!

Da ich morgen früh zu einer Besprechung im der Reichssportführung nach Berlin reisen muss und von dort in Golfangelegenheiten Hamburg besuchen soll, darf ich Sie bitten, mein Fernbleiben bei der sitzung betreffend Neubesetzung des Lehrstuhls für slavische Philologie am 24.Oktober entschuldigen zu wollen. Ich habe mit Kollegen Havers die Kandidaten ausführlich besprochen, sodass sich meine Anschauung vollständig mit seinem Vorschlag deckt. Ich mochte trotzdem auch hier nochmals betonen, dass für das sprachwissenschaftliche ordinariat an erster stelle in weitem Abstand von den übrigen Kandidaten Reinhold Trautmann nach meinem Dafürhalten in Frage kommt, dass ich anderseits aber E.H.Meyer nicht für geeignet haltenden alten repräsentativen Lehrstuhl an der Wiener Universität zu besetzen. Bei dem vorgesehenen Extraordinariat für slavische Literaturgeschichte und Volkskunde verdient unser Kollege Jagoditsch weit vorangestellt zu werden.

Mit Heil Hitler !

Waution Winhlu 
A b stract: Records of a Job Episode. Literature on Dmytro Tschižewskyj in the Archives of the University of Vienna. This article deals with a Vienna episode in Dmytro Tschižewskyj's biography (1894-1977), namely his application for a post at the Slavic Department of the University of Vienna in 1938. The history of this episode is reconstructed on the basis of documents in the University Archives: 1) the record of the meeting, 2) Tschižewskyj's autobiography, 3) Tschižewskyj's list of publications, 4) a letter to the Ministry of Education stating the results of the meeting, 5) the candidate's data, 6) a note about the absent professor.

K e y w ords: Dmytro Tschižewskyj, the Slavic Department of the University of Vienna Roman Mnich

Akademia Podlaska, Wydział Nauk Humanistycznych

Instytut Filologii Polskiej

ul. G. Orlicz-Dreszera 19/21, paw. A

08-110 Siedlce, Polen

mnichrw@yahoo.de 